\title{
A ESCALA GEOGRÁFICA NOS DOCUMENTOS OFICIAIS
}

Francisco Tomaz de Moura Júnior

Universidade Federal de Goiás/Regional Jataí, Programa de Pós-graduação em Geografia, Jataí, GO, Brasil fthomaz-junior@hotmail.com

Suzana Ribeiro Lima Oliveira Universidade Federal de Goiás/Regional Jataí, Unidade Acadêmica Especial de Estudos Geográficos, Jataí, GO,

\begin{abstract}
RESUMO
O presente artigo constitui-se em um desdobramento de um Trabalho Final de Curso (TFC), desenvolvido na Universidade Federal de Goiás/Regional Jataí, cujo escopo era compreender como o conceito de escala geográfica aparecia nos documentos oficiais. Para isso, realizou-se uma revisão das discussões sobre o currículo na literatura e, posteriormente, uma análise documental dos Parâmetros Curriculares Nacionais (PCNs), das Orientações Educacionais Complementares aos Parâmetros Curriculares Nacionais $(\mathrm{PCN}+)$, da Base Nacional Comum Curricular (BNCC) e do Currículo de Referência do Estado de Goiás a fim de identificar nesses documentos como aparece o conceito de escala geográfica. A partir dessa análise, pode-se concluir que o referido conceito aparece muito timidamente quando não associado ao conceito de escala cartográfica.
\end{abstract}

Palavras-chave: Currículo. Ensino de Geografia. Escala.

\section{THE GEOGRAPHICAL SCALE IN OFFICIAL DOCUMENTS}

\begin{abstract}
The present work constitutes an improvement of a Final Course Assignment, developed at the Federal University of Goiás/Jataí Regional, which the scope was to comprehend how the concept of geographical scale appeared in the official documents. For this, a review of the discussions about the curriculum in the literature and, after, a documentary analysis of the National Curricular Parameters, the Complementary Educational Guidelines to National Curricular Parameters, the National Curricular Common Base and the Reference Curriculum of the State of Goiás were realized to identify in these documents how the concept of geographic scale appears. From this analysis, one can conclude that the referred concept appears very shyly when not associated with the concept of cartographic scale.
\end{abstract}

Keywords: Curriculum. Geography teaching. Scale.

\section{INTRODUÇÃO}

O currículo se constitui como um "espaço" de disputas sociais, políticas, educacionais e ideológicas, sendo por meio dele definido aquele conhecimento que é socialmente valorizado, ou seja, o conhecimento que se pretende que os alunos aprendam durante a vida escolar (PEREIRA, 2015).

Dessa forma, realizou-se uma análise documental sobre os documentos curriculares oficiais, com destaque aos Parâmetros Curriculares Nacionais (PCNs), do ensino fundamental, anos finais e ensino médio, as Orientações Educacionais Complementares aos Parâmetros Curriculares Nacionais (PCN+), a Base Nacional Comum Curricular (BNCC), aprovada pelo Conselho Nacional de Educação em 15/12/2017 e homologada em 20/12/2017 e o Currículo de Referência do Estado de Goiás, visando identificar, nos referidos documentos, como aparecem ou quais conteúdos podem ser usados para potencializar a construção pelo aluno do conceito de escala geográfica, entendendo-o como um "conhecimento poderoso" (YOUNG, 2016).

A opção pela análise documental se justifica, pois, corresponde à investigação de documentos e registros oficiais de determinada instituição, fato ou sociedade (LAKATOS e MARCONI, 2003). Ela é reveladora de uma conjuntura social, de modo que eles dizem muito sobre uma sociedade, sobre quem a conduz e a

\begin{tabular}{llllll}
\hline Caminhos de Geografia & Uberlândia & v. 21, n. 73 & Mar/2020 & p. 506-517 & Página 506
\end{tabular}


relação que essas pessoas ou grupos têm com o conhecimento: sua valorização ou desvalorização, o que é desejado que os alunos conheçam ou desconheçam, dentre outros pontos.

\section{O CURRÍCULO COMO ESPAÇO DE DISPUTA}

Dito isso, é necessário antes de partirmos para análise dos documentos oficiais propriamente ditos, expressar o que se entende por currículo, sobre conhecimento poderoso e o porquê do conceito de escala geográfica ser considerado um conhecimento poderoso. Para isso, destaca-se o fato de que a realidade é única, sendo, todavia, a leitura dessa realidade feita a partir de saberes e de escolhas, intencionais ou não, e por meio de estratégias que buscam conhecimento sobre essa realidade, de modo que cada ciência, a partir de seus objetos, conceitos e métodos de análise, privilegia uma faceta do real em detrimento de outras (CALLAl, 2015).

Assim, é deveras necessário não perder de vista o fato de que o conhecimento é produzido socialmente, com base em um contexto e a partir de escolhas que são casuais ou programadas e que a construção do conhecimento é sempre permeada por relações de poder, sendo fruto de uma sociedade contraditória e conflituosa, logo, não poderia ser ele apolítico ou aconflitual.

Pode-se, portanto, dizer que,

O currículo escolar não é neutro, mas, ao ser resultado de escolhas, é ligado a interesses bem determinados. E esses interesses decorrem de muitos âmbitos, desde o tipo de instituição escolar, o tipo de professor, a estrutura de organização pedagógica da escola, os aspectos culturais do lugar onde ela se insere, até o tipo de alunos (CALLAI, 2015, p. 225).

Contraditoriamente, afirmar que o currículo é permeado por influências e interesses diversos não pode "ser traduzido pelo alijamento e pela desconsideração do valor dos conhecimentos das disciplinas escolares na formação intelectual dos alunos" (ASCENÇÃO et al., 2017, p. 133).

Soma-se a isso a percepção do currículo como um "espaço público", ou seja, como um princípio público de hierarquização do conhecimento, ainda que permeado por interesses privados, especialmente aqueles ligados ao mercado, definidor do que é importante que a juventude escolar de uma cidade, um estado ou mesmo um país deva saber/aprender.

Sobre isso, assevera Pereira (2015),

El currículo, define pues lo público. En un sentido amplio, el currículo se opne por principio a lo privativo, pues coloca al orden formal del conocimiento en una estrutura superior de los saberes. Asegura, al mismo tiempo, que por médio de ellos, los miembros de una sociedad (y me atrevo a señalar, de varias culturas, como en el caso chileno [e ao brasileiro, por analogia]) aquellos saberes por medios de los cuales participarán de los beneficios de una actuación social sino eficiente, al menos, contextualizada y pertinente (PEREIRA, 2015, p. 113-114).

Ora, se o currículo é um "espaço público", tão importante quanto seu estatuto é o fato de que seu conteúdo não é uma simples organização e hierarquização de conteúdos num rol temático que deve ser trabalhado pelo professor. Em verdade, o currículo se constitui como a eleição de uma série de conceitos, aos quais os alunos devem ter acesso por meio dos conteúdos (ASCENÇÃO et al., 2017).

Assim, ao abordar determinado conteúdo, como exemplo a urbanização ou as cidades, o professor deve ser capaz de levar o aluno para além de sua vivência imediata, de modo que, ao abordar a cidade teoricamente, ele perceba as características de sua cidade, mas também aquelas características que são inerentes a qualquer cidade daquele período e daquele espaço tratado, passando dos "conceitos cotidianos" aos "conceitos científicos" (VIGOTSKY, 1993).

O conhecimento, portanto, é propulsor de uma liberdade; e o currículo, o caminho para sua realização, uma liberdade para pensar o que não foi pensado e repensar o que está posto. "A experiência, por si só, não nos dá o direito a essas liberdades; a liberdade pode ser um direito de todos, mas é preciso trabalhar por ela e aprendê-la, por mais distante que o conhecimento emancipatório possa parecer" (YOUNG, 2016, p. 31).

A partir daí, com base em Pereira (2015), delineiam-se algumas características do currículo que se acredita serem essenciais como:

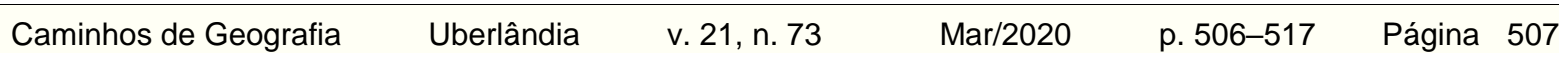


- Possui um caráter universalizante: o currículo possui uma condição prescritiva cuja pretensão é generalista e universal (PEREIRA, 2015), ou seja, em sua gênese o currículo não possui nenhum caráter excludente, podendo ser contestado sua realização, visando atingir a todos os alunos, sejam eles de escolas públicas ou privadas;

- É explicito, se apresenta a todos: "se apresenta como un marco general y enrelación a su potencial concreción llama a una batería de instrumentos que viabilizan su aplicación" (PEREIRA, 2015, p. 114);

- Apesar de prescritivo, comporta aberturas: o currículo traz em si aquele conhecimento que é tido como socialmente valorizado, que todos os estudantes devam aprender, todavia, a forma como se dará essa apreensão a partir dos conteúdos (aportes para a construção de conceitos) é realizado durante o processo de mediação pedagógica em que aluno, conteúdo e professor estão numa relação dialética entre si e com o contexto escolar e social mais amplo (PEREIRA, 2015).

Ressalta-se aqui, uma diferença entre as formulações ou métodos didático-pedagógicos e o currículo, pois,

Referem-se às responsabilidades distintas de formuladores de currículo e de professores, e cada um depende do outro. Enquanto os professores não podem, eles próprios, criar um currículo, mas precisam dele para guiá-los no que devem ensinar, os formuladores de currículos apenas podem estipular os conceitos importantes aos quais os alunos precisam ter acesso. Os formuladores de currículo contam com os professores para motivar os estudantes e transformar esses conceitos em uma realidade para os alunos (YOUNG, 2011, p. 612-613).

Dessa forma, é imprescindível a distinção entre formulações curriculares e prática docente, uma vez que, ainda que o professor deva se valer das experiências cotidianas dos alunos e o que os motivam estar ali, não deve se limitar a elas, pois, é função primeira da escola a difusão do conhecimento, mediante a construção de conceitos pelos alunos, sendo, portanto, bem diferente de tornar as experiências dos mesmos elementos do currículo (YOUNG, 2011).

Enfatiza-se, pois, que,

O conhecimento curricular - ou disciplinar - é independente do contexto, diferentemente do conhecimento baseado na experiência que os alunos trazem para a escola, que está diretamente ligado aos contextos nos quais as pessoas vivem e dentro dos quais é adquirido. Dessa maneira, a tarefa do professor, na construção do currículo escolar, é permitir que os alunos se envolvam com o currículo e avancem para além da sua experiência. Por isso, é tão importante que os professores entendam a diferença entre currículo e pedagogia - ou as atividades e as concepções dos professores (YOUNG, 2016, p. 34, grifo do autor).

Tem-se ainda como problemática a instrumentalização do currículo por uma lógica econômica ditada, muitas vezes, por organismos internacionais, de forma que, em nosso contexto atual, as políticas educacionais e curriculares incorporam elementos de uma lógica neoliberal, só sendo possível compreendê-las no movimento de sua relação com a sociedade, o Estado e a educação, bem como a política de desenvolvimento, as demandas do mercado e a conjuntura social e política do país (PIRES, 2017).

Tal fato reforça o argumento de que a construção de um currículo pressupõe um processo não linear, conflituoso e mesmo contraditório, pois, "depende dos agentes se apresentarem para contribuir, disputar e lutar pelos sentidos e significados de uma política curricular" (PIRES, 2017, p. 244).

Essa instrumentalização, muitas vezes, reforça deficiências no entendimento e aplicabilidade do currículo e que, num cenário mais amplo, são também da Educação. Observa-se como reconfiguração curricular a sua divisão por áreas de conhecimento, toma-se como exemplo a forma como está organizada a BNCC, tendo na interdisciplinaridade um dos seus baluartes.

Nota-se, aqui, uma íntima correlação com aquilo que Harvey (2005) descreveu como regime de acumulação flexível que, a partir das décadas de 1960 e 1970 desemboca no modelo toyotista, substituindo, em muitos aspectos o clássico modelo fordista. Isso se transforma no início do século XXI na demanda do mercado trabalho por um sujeito que seja multidisciplinar, flexível, que saiba trabalhar em grupo, resolver problemas e solucionar crises, fato que reverbera na educação.

$\begin{array}{lllll}\text { Caminhos de Geografia } \quad \text { Uberlândia } & \text { v. 21, n. } 73 \quad \text { Mar/2020 } & \text { p. 506-517 } & \text { Página } 508\end{array}$


Em âmbito educacional, contudo, a interdisciplinaridade representa um empecilho à construção de uma escola e educação que favoreça a cidadania de fato, haja vista que inviabiliza a existência de um conhecimento poderoso. O conhecimento poderoso conduz, obrigatoriamente, ao atendimento de duas questões: "(i) há um 'melhor conhecimento' em todas as áreas e (ii) a base de todas as decisões sobre conhecimento no currículo é a ideia de diferenciação, de que existem diferentes tipos de conhecimento" (YOUNG, 2016, p. 33).

O primeiro quesito faz referência à existência de um conhecimento que seja "melhor", não no sentido de emissão de juízos de valores por um sujeito particular, mas no sentido de que, objetivamente, alguns conhecimentos ou, mais precisamente, alguns conceitos presentes nos conteúdos, melhor ajudam os alunos a compreender a realidade na qual estão inseridos e, entendendo-a, possam transformá-la (YOUNG, 2016).

Pode-se, por exemplo, defender que existe um conjunto de conceitos e formas de análise própria da Geografia que, aliado a sua robustez teórica, permite aos alunos adquirir as condições de formar conceitos, sendo estes fundamentais para se pensar-decodificar-analisar-compreender o espaço geográfico, sem os quais os alunos estariam restritos aos elementos de sua experiência diária (PIRES, 2017).

No que tange ao segundo ponto, advoga-se em favor de um currículo estruturado em disciplinas, pois estas correspondem ao conhecimento existente elaborado por comunidades de especialistas, aos quais intitulamos como comunidades disciplinares, sendo formas organizadas socialmente cuja finalidade reside na produção de novos conhecimentos (YOUNG, 2016).

Tais comunidades, por sua vez, possuem histórias e tradições diferentes atreladas ao processo pelo qual se desenvolveu cada ciência. São por meio dessas comunidades que diferentes professores, escolas e universidades, bem como estudantes de todos os níveis se encontram ligados uns aos outros, sendo cada dia mais comum comunidades de diferentes países se ligarem por meio de periódicos, congressos e pela internet (YOUNG, 2011).

Aliado a isso, tem-se que as disciplinas não são prescrições ou simples instruções, de forma que,

Ao adquirirem conhecimentos das disciplinas, eles [os alunos] estão ingressando naquelas "comunidades de especialistas", cada uma com suas diferentes histórias, tradições e modos de trabalhar. As disciplinas, portanto, têm três papéis num "currículo de engajamento". O primeiro é um papel curricular. As disciplinas garantem, por meio de seus elos com o processo de produção de novos conhecimentos, que os estudantes tenham acesso ao conhecimento mais confiável disponível em campos particulares. O segundo papel é pedagógico. As disciplinas oferecem pontes aos aprendizes para que passem de seus "conceitos cotidianos" aos "conceitos teóricos" a elas associados. O terceiro é um papel gerador de identidade para professores e aprendizes. As disciplinas são cruciais para o senso de identidade dos professores como membros de uma profissão (YOUNG, 2011, p. 617).

O conhecimento poderoso, portanto, é um conhecimento que permite aos alunos compreenderem o mundo no qual estão inseridos e a forma como se dá essa inserção para que, a partir disso, possam transformar sua situação e o mundo. Young (2007) falando sobre isso e, indo além, afirmando sobre o importante papel da escola nesse processo, sentencia:

As escolas devem perguntar: "Este currículo é um meio para que os alunos possam adquirir conhecimento poderoso?". Para crianças de lares desfavorecidos, a participação ativa na escola pode ser a única oportunidade de adquirirem conhecimento poderoso e serem capazes de caminhar, ao menos intelectualmente, para além de suas circunstâncias locais e particulares. Não há nenhuma utilidade para os alunos em se construir um currículo em torno da sua experiência, para que este currículo possa ser validado e, como resultado, deixá-los sempre na mesma condição (YOUNG, 2007, p. 1297).

Alguns, contrários a essa concepção de currículo, poderiam dizer que ela é tradicionalista e reproduz desigualdades na aprendizagem e/ou que o currículo deve ser centrado no sujeito. A eles indicamos, como faz Young (2011), que crer que o currículo escolar, em particular, e a educação, em geral, possa sanar desigualdades provenientes de outras áreas da vida é no mínimo ingenuidade, bem como é a reprodução de um discurso que tem na escola a imagem de "salvação" e/ou capaz de resolver todas as mazelas sociais.

$\begin{array}{llllll}\text { Caminhos de Geografia } & \text { Uberlândia } & \text { v. 21, n. } 73 & \text { Mar/2020 } & \text { p. 506-517 Página } 509\end{array}$


Sabe-se muito bem que a educação de qualidade é fundamental ao combate da desigualdade e da violência estrutural que se instituiu no Brasil, contudo, isolada de outras políticas sociais, de distribuição de renda, moradia, saúde e saneamento, aquela se mostra totalmente inócua. Pois, "o bem-estar humano é um objetivo importante para todas as sociedades; contudo, é tanto um objetivo para famílias e comunidades quanto para escolas, e diz pouco sobre o papel específico das escolas" (YOUNG, 2011, p. $612)$.

O conhecimento estruturado em disciplinas expressa valores que são universais, tendo os seres humanos como iguais, sem distinção de classe, gênero, cor, etnia ou qualquer outra diferença (YOUNG, 2011), sendo, por exemplo, impensado a classe trabalhadora, num contexto de disputas de classes, não se valer dos conhecimentos que foram desenvolvidos por agentes hegemônicos e/ou contaram com financiamento das instituições privadas.

Ao argumento de que o currículo deve ter como centralidade o sujeito, aponta-se a escola como locus do conhecimento, fato que the confere um estatuto de difusão do saber acumulado ao logo dos séculos, não podendo se limitar ao cotidiano, ou seja, àquela realidade imediata dos alunos e da escola sob pena de se criar aquilo que Libâneo (2012) chamou de escola de acolhimento social.

Assim, entende-se o currículo como um conjunto de conceitos, expresso por meio de conteúdos coerentemente organizados, construído a partir de discussões coletivas num processo não linear, conflituoso, contraditório e desigual quanto ao grau de ação dos sujeitos. A partir disso, passa-se a discutir as razões pelas quais o conceito de escala geográfica deve ser considerado poderoso.

Antes, porém, é preciso um adendo: os conceitos geográficos formados pelos alunos a partir de sua relação com o conteúdo e o professor, em que se faz uso da realidade cotidiana dos alunos, não constitui um fim em si mesmo, mas um instrumental teórico que Ihes permite entender a espacialidade do fenômeno, suas causas, correlações e consequências (ASCENÇÃO e VALADÃO, 2014).

É nesse contexto que o conceito de escala geográfica se faz necessário: como artifício teórico-conceitual responsável por tornar visível aqueles fenômenos que, num primeiro olhar, são tidos como naturais (CASTRO, 1992); e como instância material de reprodução do capital, integrado à teoria do desenvolvimento desigual e combinado de forma que visa dar coerência à produção do espaço em níveis diferentes, organizados e hierarquizados conforme o movimento do próprio capital (MELAZZO e CASTRO, 2007).

Dessa forma, o referido conceito deve ser entendido como estruturante da ciência geográfica (ASCENÇÃO e VALADÃO, 2014), pois possibilita, junto aos conceitos de espaço e tempo (também estruturantes) e aos conceitos analíticos, como território, lugar, paisagem, dentre outros, ordenados numa espécie de constelação de conceitos (HAESBAERT, 2014), o desenvolvimento de um raciocínio geográfico que permita aos alunos compreender os fatores exógenos e endógenos ao local que, conjuntamente, contribuem para materialização dos fenômenos pelo espaço.

Logo, pode-se dizer que,

O raciocínio geográfico refere-se a uma forma de exercitar o pensamento espacial, por intermédio de determinados princípios (analogia, conexão, diferenciação, distribuição, extensão, localização e ordem) para representar e interpretar o mundo em permanente transformação, compreender as relações entre sociedade e natureza, pensar e resolver problemas gerados na vida cotidiana (PIRES, 2017, p. 256).

Soma-se a isso a possibilidade de, a partir desse raciocínio, o aluno identificar e correlacionar também elementos como dispersão e concentração de técnicas, equipamentos públicos, informação, entre outros, sempre privilegiando as diversas articulações que se materializam no espaço, sem qualquer linearidade ou hierarquia no "aumento" ou "diminuição" das escalas geográficas.

Ainda no que tange ao raciocínio geográfico, Ascenção e Valadão (2014) estabelecem um tripé metodológico capaz de revelar a espacialidade do fenômeno, sendo constituído pelos elementos localizardescrever-interpretar que coaduna com as questões geográficas que tomamos como referência neste trabalho: "Onde?", "Por que aí?" (FOUCHER, 1989) e "Como é esse lugar?" (CAVALCANTI, 2012), tendo a escala geográfica papel privilegiado.

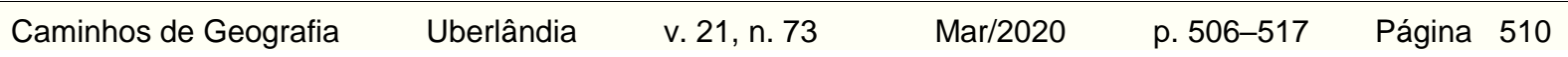


Explicando esse tripé metodológico, os autores expressam:

\begin{abstract}
A localização é assumida para mais do que seu referencial cartesiano, que a baliza através de coordenadas geográficas. Localizar nessa perspectiva significa indicar os atributos do fenômeno e dos demais constituintes do espaço onde esse se materializa/materializou. A distribuição (dispersão/concentração) de tais atributos do fenômeno e de seu local de ocorrência constituirá a descrição. Essa, em associação com a localização, permitirá a produção de interpretações dos processos que atuam sobre/a partir do fenômeno e que em interação aos demais componentes presentes numa dada localidade, produzem certa espacialidade. Todo esse movimento se estabelece através da interação entre os conceitos estruturantes [espaço, tempo e escala], o tripé metodológico e os processos - físicos e antropogênicos -, numa relação de interdependência (ASCENÇÃO e VALADÃO, 2014, p. 6).
\end{abstract}

Assim, pode-se colocar que o conceito de escala geográfica constitui um conhecimento poderoso, porque: (a) é um conhecimento disciplinar, ou seja, pertencente a uma comunidade de especialistas que se ligam por meio da Geografia, (b) é um conhecimento objetivamente "melhor" ou, dito em outros termos, necessário, uma vez que é a partir dele que pode o aluno desenvolver um raciocínio geográfico que o permita estabelecer conexões, analogias, diferenciações, além de localizar e interpretar uma dada espacialidade, desnudando seus constituintes, endógenos e exógenos, desmistificando uma suposta naturalidade de um espaço desigual.

Cabe, por conseguinte, identificar como esse conceito aparece nos documentos oficiais, ou melhor, quais conteúdos propiciam o desenvolvimento desse conceito. Para isso, começa-se por uma análise mais geral dos documentos oficiais.

\title{
OS DOCUMENTOS OFICIAIS E O CONCEITO DE ESCALA GEOGRÁFICA
}

Os PCNs são documentos oficiais redigidos sob a tutela do Ministério da Educação (MEC), sendo publicados em 1997 e 2000, respectivamente, referindo ao ensino fundamental e ensino médio. Seu fundamento encontra-se em legislações anteriores, especialmente, na Constituição Federal de 1988, com destaque aos artigos 205 e 206 que estabelecem como princípios o direito à educação, à igualdade nas condições de ensino, à liberdade de ensinar e aprender, ao pluralismo de ideias, dentre outros (BRASIL, 2012), e na Lei de Diretrizes e Bases da Educação Nacional (LDBEN), Lei no 9.394 de 1996 (BRASIL, 2017).

A LDBEN (Lei ํํ 9.394/96) é responsável por uma regulamentação mais específica da educação nacional, trazendo em seu texto a divisão da educação brasileira em níveis e modalidades (BRASIL, 2017), lembrando que tanto a Constituição de 1988 quanto a referida lei foram pensadas e feitas num contexto de redemocratização e de valorização da educação, em nível nacional como também em nível internacional, e, por outro lado, de crescentes avanços das políticas neoliberais sobre a educação.

Dessa forma, e entendendo o currículo como fruto de disputas, inerentes à própria sociedade e ao conhecimento, é comum encontrar nesse e em outros documentos contradições e mesmo incoerências internas.

No que tange à disciplina de Geografia, os PCNs expressam como seu objetivo:

\begin{abstract}
Estudar as relações entre o processo histórico na formação das sociedades humanas e o funcionamento da natureza por meio da leitura do lugar, do território, a partir de sua paisagem. Na busca dessa abordagem relacional, trabalha com diferentes noções espaciais e temporais, bem como com os fenômenos sociais, culturais e naturais característicos de cada paisagem, para permitir uma compreensão processual e dinâmica de sua constituição, para identificar e relacionar aquilo que na paisagem representa as heranças das sucessivas relações no tempo entre a sociedade e a natureza em sua interação (BRASIL, 1998, p. 26).
\end{abstract}

Nesse intuito, num primeiro momento é feita uma contextualização do processo de constituição e desenvolvimento dessa ciência, desde sua institucionalização, a hegemonia da Geografia tradicional e do conceito de região, passando pelo movimento de renovação e ascensão da Geografia radical (marxista), com a valorização do espaço e do território, até a retomada de conceitos como paisagem e lugar, agora numa perspectiva cultural, muito atrelada ao sujeito, pela chamada Geografia cultural (BRASIL, 1998, 2002).

Caminhos de Geografia Uberlândia $\quad$ v. 21, n. 73 $\quad$ Mar/2020 $\quad$ p. 506-517 Página 511


Contrariamente, o próprio texto traz a discrepância entre a chamada Geografia acadêmica e seu ensino, pois, enquanto a primeira avança, se reinventa, cria novas abordagens, teorias, métodos de análise, o ensino de Geografia ainda se encontra mnemônico, descritivo, pouco atrativo, centrado numa lógica estanque em que não se explora (ou pouco se explora) as correlações e a espacialidade do fenômeno (ASCENÇÃO e VALADÃO, 2014).

Além disso, tem-se uma valorização do cotidiano do aluno, suas experiências e percepções, porquanto se coloca ser "fundamental que a vivência do aluno seja valorizada e que ele possa perceber que a Geografia faz parte do seu cotidiano, trazendo para o interior da sala de aula, com a ajuda do professor, a sua experiência" (BRASIL, 1998, p. 30).

Acorda-se com a valorização da experiência dos alunos, todavia, considerando a escola enquanto locus do conhecimento e um espaço promotor de liberdade, inclusive da própria experiência, deve o professor se valer da experiência do aluno sem jamais se restringir a ela (YOUNG, 2016).

A distribuição e eleição dos conteúdos, por sua vez, se dão a partir de eixos temáticos próprios da Geografia que, em regra, discutem a relação dos fenômenos espaciais e suas implicações para a sociedade e por temas transversais (ética, pluralidade cultural, trabalho e consumo, saúde, orientação sexual, meio ambiente) que fazem parte do cotidiano do aluno e deveriam ser incluídas como preocupações do professor de Geografia (BRASIL, 1998).

O conceito de escala geográfica, por sua vez, aparece timidamente nos objetivos do terceiro ciclo quando se coloca como objetivo: "compreender a escala de importância no tempo e no espaço do local e do global e da multiplicidade de vivências com os lugares" (BRASIL, 1998, p. 53). Nota-se um favorecimento de uma dualidade local/global e, mesmo que sejam as escalas "mais importantes", em momento nenhum são capazes de dissolver o regional, seja macro, meso ou microrregional, nem o nacional.

Assim, o privilégio dado à relação local/global pode incorrer no ocultamento de relações que se dão a nível microrregional, como a divisão territorial do trabalho e o desenvolvimento desigual e combinado que se apropria seletivamente de regiões, causando uma especialização produtiva dos lugares.

Um exemplo dessa situação é o que ocorre no estado de Goiás, em que, o Sudoeste de Goiás se constitui uma microrregião especializada na produção de grãos e articulada à cadeia produtiva de carne-grãos, favorecida pela especialização da microrregião de Catalão, responsável pela extração e processamento de minerais, especialmente aqueles destinados à fabricação de adubos e na produção, distribuição e montagem de peças e máquinas agrícolas.

Uma possibilidade de se trabalhar e desenvolver o conceito de escala com maior propriedade aparece no segundo eixo, especificamente no item "litosfera e movimentos tectônicos: existem terremotos no Brasil?" (BRASIL, 1998, p. 63). Aqui, pode-se explorar a espacialidade do fenômeno exercitando o raciocínio geográfico entorno de sua extensão, indo além, pode-se utilizar esse conteúdo a fim de explorar a distinção entre a escala cartográfica e geográfica.

Por conseguinte, é potencial o uso do conteúdo de "movimentos tectônicos" para correlacionar que, numa escala geográfica, esse fenômeno é representado por uma grande extensão territorial - uma escala planetária/grande - enquanto que, numa escala cartográfica, ou seja, da representação material, no papel ou em meio digital, por ocupar uma grande área, terá que ser reduzido milhões de vezes, constituindo ao final uma escala pequena (OLIVEIRA, 2009).

Da mesma forma, é possível utilizar os conteúdos de clima, massas de ar, a produção de lixo, os problemas ambientais como vazamentos de petróleo no oceano, efeito estufa ou mesmo as questões de natureza social, em que se pode articular ao tratar da agricultura o destino da produção e/ou a compra de insumos da qual ela depende, o comércio internacional (sites de e-commerce), das migrações, nacionais e/ou internacionais, especialmente, em tempos que são recorrentes os movimentos migratórios de refugiados das guerras na Síria, Líbia, Iraque, entre outros países.

O eixo "Cartografia no ensino fundamental", em que se coloca a dualidade aluno mapeador/aluno leitor (ALMEIDA, 2009), traz como item "os conceitos de escala e suas diferenciações e importância para as análises espaciais nos estudos de Geografia" (BRASIL, 1998, p. 80), todavia, no desenvolver do item observa-se que a discussão perde parte de seu potencial, pois se centra, quase que exclusivamente, na escala cartográfica.

Os PCNs do ensino médio, por sua vez, trazem no item "competências e habilidades a serem desenvolvidas pela Geografia", uma série de aptidões que os alunos devem desenvolver, dentre elas, destaca-se: "ler, analisar e interpretar os códigos específicos da Geografia (mapas, gráficos, tabelas etc.),

$\begin{array}{lllll}\text { Caminhos de Geografia } & \text { Uberlândia } & \text { v. 21, n. } 73 & \text { Mar/2020 } & \text { p. 506-517 Página } 512\end{array}$


considerando-os como elementos de representação de fatos e fenômenos espaciais e/ou espacializados" e "reconhecer os fenômenos espaciais a partir da seleção, comparação e interpretação, identificando as singularidades ou generalidades de cada lugar, paisagem ou território" (BRASIL, 2002, p. 35).

Acredita-se que, apesar de possuírem um forte caráter utilitarista e centrado em aspectos técnicos, especialmente aqueles vinculados à cartografia, essas "competências" coadunam com aquilo que Pires (2017) estabelece como raciocínio geográfico.

Juntamente aos PCNs, do ensino fundamental e médio, têm-se os PCN+ que visam preencher lacunas deixadas nos PCNs, além de serem mais enfáticas em determinados pontos.

Neles o conceito de escala geográfica ganha destaque ao passo que é apresentado de maneira distinta da escala cartográfica, sendo uma visão que muito se aproxima daquilo que Castro $(1992 ; 2014)$ estabelece como ideal do conceito, como se vê:

Distinguem-se dois tipos ou duas visões básicas: a escala cartográfica e a escala geográfica. A primeira delas é, a priori, uma relação matemática que implica uma relação numérica entre a realidade concreta e a realidade representada cartograficamente. No caso da escala geográfica, trata-se de uma visão relativa a elementos componentes do espaço geográfico, tomada a partir de um direcionamento do olhar científico: uma escala de análise que procura responder os problemas referentes à distribuição dos fenômenos (BRASIL, 2006, p. 56, grifo do autor).

Aliado a essa conceituação, tem-se como auxílio um conjunto de outros conceitos e conteúdos que são potencialmente importantes para a construção do conceito de escala e o desenvolvimento do raciocínio geográfico, sendo eles: a globalização, as técnicas e as redes. O primeiro corresponde a um conteúdo, sendo os dois seguintes conceitos a ele articulados. Esse conteúdo se mostra potencialmente importante, pois, a partir dele, pode o professor mobilizar o aluno a identificar no local, o lugar de sua vivência, aqueles elementos que, mesmo estando ali, em algum momento (produção, circulação e/ou consumo) estiveram vinculados à outra(s) escala(s).

Além disso, pode-se citar o tema da "dinâmica da superfície hídrica" que se articula com "os problemas ambientais e suas origens", pois, como se sabe, cursos d'água percorrem extensas áreas dentro de um mesmo país ou recortando vários. E aqueles problemas gerados em determinado local podem impactar diversos outros, chegando a uma escala global, da mesma forma, aqueles problemas ambientais gerados numa escala global podem impactar outras escalas como a nacional, regional e, principalmente, o local.

É exemplo disso o que ocorreu com o rompimento da barragem da empresa Samarco Mineração, no município de Mariana (MG), e que acabou por comprometer a qualidade da água de todo o Rio Doce no estado de Minas Gerais e Espírito Santo, além de contaminar parte do oceano Atlântico. Tem-se aí um exemplo de como um fenômeno ocorrido no local impacta todo um sistema (correntes marítimas, fauna e flora marinha, etc.) que é global.

Isto posto, sobre as últimas mudanças curriculares no Brasil (Reforma do Ensino Médio e BNCC), pode-se dizer que "los cambios en el currículo nunca son azarosos, nunca son casuales. Responden a coyunturas - y en certa media - se vislumbran en es cenarios políticos de potenciales actuaciones de los sujeitos membros de una sociedade" (PEREIRA, 2015, p. 107). A criação de uma base nacional comum, portanto, responde a demandas da sociedade, do Estado, do mercado e da própria educação.

A base corresponde a uma centralização do currículo, uma espécie de nacionalização e unificação daquilo que se deve ensinar/aprender, corresponde também a um plano normativo-prescritivo base à elaboração dos currículos estaduais e municipais, juntamente com a elaboração de Projetos Políticos Pedagógicos (PPP) das escolas, públicas e privadas, em acordo com os contextos nos quais se inserem, a diversidade dos alunos e suas etapas de escolarização (PIRES, 2017).

Ela possui como princípios orientadores a flexibilização, a interdisciplinaridade e a contextualização cujos objetivos são o ingresso e a permanência do sujeito. Estruturalmente, ela está dividida em áreas de conhecimentos, estando o componente de Geografia dentro da área de Ciência Humanas. Já expressamos nosso posicionamento contrário a essa alocação, pois constitui um obstáculo ao desenvolvimento e apropriação, pelos alunos, de um conhecimento poderoso (YOUNG, 2011), ainda mais porque compreendendo as disciplinas, o aluno tem condições de estabelecer correlações com outras comunidades disciplinares.

$\begin{array}{lllll}\text { Caminhos de Geografia } & \text { Uberlândia } & \text { v. 21, n. } 73 & \text { Mar/2020 } & \text { p. 506-517 }\end{array}$ Página 513


Ainda a respeito dessa dissolução da Geografia nessa grande área, recorremos a Pereira (2015) quando, comentando as reformas curriculares ocorridas no Chile, que muito se aproximam das que estão sendo implementadas no Brasil, problematiza:

Travestir a la Geografía de disciplina anexa, secundaria, formó parte del proyecto educativo neoliberal [...], que no vio con buenos ojos, cómo una parte importante de la legitimación del sistema alcanzado, se resquebrajaba a causa de ese "subversivo, incendiário y peligroso conocimiento sobre las formas de producir y habitar el mundo" que dejó de estar en la enunciaciones curriculares y se transformo en conocimiento de vida, en saber de experiencia (PEREIRA, 2015, p. 107).

Todavia, como qualquer currículo, é inegável que a BNCC traz avanços e recuos no tocante à educação nacional, o que se coloca é a defesa de uma base nacional comum estruturada em disciplinas, pois, acredita-se serem estas necessárias ao desenvolvimento do conhecimento poderoso.

Pari passu com isso, compreende-se que uma das comunidades disciplinares que tem muito a contribuir com a educação básica é a geográfica, pois, é ela que visa problematizar a inter-relação entre sociedade e natureza, suas interações no espaço geográfico, bem como as consequências advindas delas. É, dessa forma, por meio de escalas geográficas e temporais que pode o aluno realizar uma leitura do mundo, conhecendo sua realidade e o modo como ele se insere nela. Sem esse instrumental teórico-conceitual da ciência geográfica e seus métodos investigativos,

O aluno pouco avançará no sentido de conseguir interpretar, analisar e compreender o mundo, bem como aplicar os conhecimentos adquiridos nesse processo ao seu contexto de vida. Isso reforça, portanto, a importância da Geografia na leitura/compreensão do mundo e justifica a presença dela como componente curricular na Educação Básica (PIRES, 2017, p. 239-240).

Em se tratando dos conteúdos propícios à construção do conceito de escala geográfica, tem-se que, a BNCC possui uma peculiar divisão, em que, nos anos iniciais do ensino fundamental, os conteúdos a serem aprendidos, estão ligados a temáticas vinculadas ao ambiente escolar e seu entorno (bairro, cidade, etc.), valorizando suas experiências, desejos e anseios. Nos anos finais, por sua vez, pretende-se uma articulação dessas experiências com outras, mais gerais como o estado, o país e o globo, valorizando-os como sujeitos em formação que se inserem numa cultura permeada por influência digital, no mercado como consumidores e protagonistas (BRASIL, 2017).

Aqui, os conteúdos estão divididos em unidades temáticas, destacando-se, segundo os propósitos aqui tratados, o eixo temático "conexões e escalas", no qual o aluno deve compreender a

\begin{abstract}
Articulação de diferentes espaços e escalas de análise, possibilitando que os alunos compreendam as relações existentes entre fatos nos níveis local e global. Portanto, no decorrer do Ensino Fundamental, os alunos precisam compreender as interações multiescalares existentes entre sua vida familiar, seus grupos e espaços de convivência e as interações espaciais mais complexas (BRASIL, 2017, p. 360).
\end{abstract}

Nota-se, como ocorre nos PCNs e PCNs+, uma valorização da dualidade local/global em detrimento de outras escalas de análise como a regional e a nacional, de modo que, mesmo entendendo que a relação local/global é sobremaneira importante para a compreensão da espacialidade dos fenômenos, é necessário destacar as demais escalas, especialmente, a regional, em virtude das dimensões continentais que possui o Brasil e, mais do que isso, em virtude das disparidades culturais e econômicas existentes entre as diferentes regiões.

Na unidade "formas de representação e pensamento espacial", encontram-se os conteúdos de cartografia que têm seu escopo na "ampliação gradativa da concepção do que é um mapa e de outras formas de representação gráfica, são reunidas aprendizagens que envolvem o raciocínio geográfico” (BRASIL, 2017, p. 361), apresentando a indelével importância das formas de representação, devendo entendê-las considerando a cartografia cartesiana, mas incluindo compressão do real em uma perspectiva contextualizada.

Por fim, tem-se como objeto de análise o Currículo de Referência da Rede Estadual de Educação de Goiás, ele, como as demais orientações curriculares, também se encontra dividido por áreas do conhecimento, estando a Geografia na grande área das Ciências Humanas junto com a História, Filosofia, Sociologia e Ensino Religioso (GOIÁS, 2012).

$\begin{array}{llllll}\text { Caminhos de Geografia } & \text { Uberlândia } & \text { v. 21, n. } 73 & \text { Mar/2020 } & \text { p. 506-517 } & \text { Página } 514\end{array}$


Sua estruturação se dá entre três eixos temáticos: Físico Territorial, Social e Cartográfico. O eixo Físico Territorial corresponderia àquelas temáticas mais próximas de uma análise ambiental em que ganham destaque conteúdos como relevo, solos, geologia, clima, dentre outros. O eixo Social, por sua vez, estaria ligado a temáticas como população, urbanização, cidades, geoeconomia, migrações, questões agrárias, globalização e outras. Por fim, o eixo de Cartografia, sendo autoexplicativo é referente às questões cartográficas, orientação, lateralidade, mapas (entendendo-os para além de uma cartografia puramente cartesiana), representações e outros tipos de linguagens (GOIÁS, 2012).

Tais eixos temáticos aparecem no currículo, quase sempre, de maneira conjunta, alternando apenas a ordem de aparição. Isso se deve às múltiplas imbricações que tanto os aspectos naturais e sociais possuem, bem como as diversas formas de uso da linguagem cartográfica para representá-los.

Nele o conceito de escala geográfica aparece pela primeira vez como uma "expectativa de aprendizagem", no $1^{\circ}$ bimestre do $7^{\circ}$ ano que postula: "utilizar corretamente as escalas geográficas (regional, nacional, mundial) na localização e representação dos Estados no Brasil e desse País no continente americano, e no mundo" (GOIÁS, 2012, p. 198).

Nela é visível a confusão existente entre a escala cartográfica e a geográfica, de modo que, o ideal cartesiano de localização pura em nada contribui para o entendimento confiável e a valorização do conceito. Essa visão, portanto, toma a escala geográfica como ordem de grandeza (CASTRO, 2014), permeando todo o currículo estadual e reforçando a confusão entre os conceitos de escalas que, mesmo contribuindo para o desenvolvimento do raciocínio geográfico, cada qual a seu modo, são conceitos distintos.

Depreende-se, portanto, das análises aqui esboçadas as seguintes considerações:

- O currículo construído coletivamente guarda múltiplas influências, sendo conflituoso e, muitas vezes, contraditório, fruto da sociedade e da organização da própria educação;

- O currículo constitui-se como um direcionador da educação nacional, sendo "recheado" por conteúdos que buscam viabilizar a construção de conceitos. Esses constituem os artifícios teórico-conceituais para realizar a análise da espacialidade dos fenômenos;

- Cada vez mais, tem-se um currículo organizado por grandes áreas do conhecimento, fato que impossibilita o desenvolvimento de um conhecimento poderoso;

- O conhecimento poderoso só é possível com a organização do conhecimento em comunidades disciplinares que Ihes concedem identidade e a partir das quais especialistas, professores e alunos se encontram ligados;

- O aluno, ao compreender uma disciplina e se apropriar de seus conceitos poderosos, poderá ir além, estabelecendo relações com outras comunidades disciplinares e se apropriando de outros conhecimentos. O que se postula é que o caminho para isso é disciplinar;

- O conhecimento poderoso é aquele que é objetivamente "melhor" e capaz de libertar o sujeito da própria experiência, ainda que o professor em sua prática docente deva se valer dela para ir além;

- O conceito de escala geográfica é um conceito poderoso que permite ao aluno desenvolver um raciocínio geográfico.

Nesse entendimento, considera-se necessária inserção com maior visibilidade do ensino da escala geográfica, oportunizando aos alunos a compreensão e contextualização do real.

\section{CONSIDERAÇÕES FINAIS}

Buscou-se, assim, a partir da literatura e analisando os documentos curriculares, defender a ideia de que 0 conceito de escala geográfica é essencial a um conhecimento poderoso, pois é a partir dele que pode o aluno emergir de fato no mundo, compreendendo a forma como está inserido e as limitações inerentes a ela, para que, com isso, possa transformar sua realidade (YOUNG, 2007, 2011, 2016).

Os documentos curriculares, nesse contexto, são expressões de relações de poder, permeados por disputas e interesses, gestados no bojo de uma relação entre a sociedade, o mercado e o Estado, não sendo sua organização ou mudança fruto do acaso, mas de demandas sociais, históricas e geográficas, que elegem determinado conteúdo como importante, devendo os alunos conhecê-los (ASCENÇÃO et al., 2017).

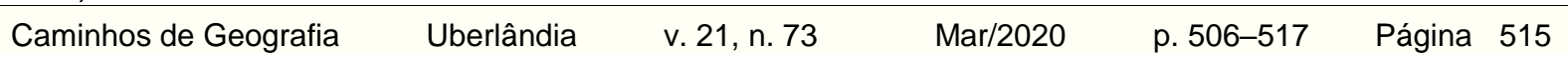


Por fim, aponta-se que os documentos oficiais timidamente ou em nada contribuem para aclarar a confusão existente entre os tipos de escalas, ainda que tragam em seus textos avanços consideráveis sobre o raciocínio geográfico.

Aliado a isso e expressando um entendimento sobre o currículo, tem-se que sua organização em disciplinas é fundamental, pois é a partir delas, ou melhor, das comunidades disciplinares que elas engendram, que pode o aluno ingressar numa área do conhecimento, se apropriando de conceitos e métodos analíticos, além de serem elas algumas das dimensões responsáveis pela (re)construção da identidade profissional docente (YOUNG, 2011).

\section{REFERÊNCIAS}

ALMEIDA, R. D. Do desenho ao mapa: iniciação cartográfica na escola. 4a․ ed. São Paulo: Contexto, 2009.

ASCENÇÃO, V. O. R.; LEITE, C. M. C.; PORTELA, M. O. B. Currículo e ensino de Geografia: um diáogo a ser posto. In: ALVES, A. O.; KHAOULE, A. M. K. (Orgs.). A Geografia no cenário das políticas públicas educacionais. Goiânia: C\&A Alfa \& Comunicações, 2017. Cap. 6, p. 125-148.

ASCENÇÃO, V. O. R.; VALADÃO, R. C. Professor de Geografia: entre o estudo do fenômeno e a interpretação da espacialidade do fenômeno. Scripta Nova: revista electrónica de Geografía e Ciencias Sociales, Barcelona, v. 18, n. 496 (3), p. 1-14, dez. 2014.

BRASIL. CÂMARA DOS DEPUTADOS. Constituição da República Federativa do Brasil. 35ạ. ed. Brasília: Câmara dos Deputados, 2012.

BRASIL. SENADO FEDERAL. LDBEN: Lei de diretrizes e bases da educação nacional. Brasília: Senado Federal/Coordenação de edições técnicas, 2017.

BRASIL. MINISTÉRIO DA EDUCAÇÃO. Base Nacional Comum Curricular (BNCC): a educação é a base. Brasília: MEC, 2017.

BRASIL. MINISTÉRIO DA EDUCAÇÃO. Orientações Educacionais Complementares aos Parâmetros Currículares Nacionais (PCN+). Brasília: MEC/SEB, 2006.

BRASIL. MINISTÉRIO DA EDUCAÇÃO. Parâmetros curriculares nacionais: geografia. Brasília: MEC/SEF, 1998.

BRASIL.MINISTÉRIO DA EDUCAÇÃO. Parâmetros curriculares nacionais: ensino médio: Parte IV: ciências humanas e suas tecnologias. Brasília: MEC/SEMTEC, 2002.

CALLAI, H. C. Temas e conteúdos no ensino de geografia. In: RABELO, K. S. P.; BUENO, M. A. (Orgs.). Currículo, políticas públicas e ensino de geografia. Goiânia: Editora da PUC/GO, 2015. Cap. 10, p. 213-230.

CASTRO, I. E. Análise geográfica e o problema epistemológico da escala. Anuário do Instituto de Geociências, São Paulo, v. 15, p. 21-25, 1992.

CASTRO, I. E. Escala e pesquisa na geografia. Problema ou solução? Espaço Aberto, Rio de Janeiro, v. 4, n. 1, p. 87-100, 2014. https://doi.org/10.36403/espacoaberto.2014.2435

CAVALCANTI, L. D. S. O ensino de geografia na escola. Campinas: Papirus, 2012.

FOUCHER, M. Lecionar a Geografia, apesar de tudo. In: VESENTINI, J. W. (Org.). Geografia e ensino: textos críticos. Campinas: Papirus, 1989. p. 13-29.

GOIÁS, S. D. E. D. E. Currículo de Referência da Rede Estadual de Educação de Goiás. Goiânia: SEDUC, 2012.

HAESBAERT, R. O espaço como categoria e sua constelação de conceitos: uma abordagem didática. In: TONINI, I. M., et al. (Orgs.). $\mathbf{O}$ ensino de geografia e suas composições curriculares. Porto Alegre: Mediação, 2014. Cap. 8, p. 109-121.

HARVEY, D. A produção capitalista do espaço. São Paulo: Annablume, 2005. 
LAKATOS, E. M.; MARCONI, M. A. Fundamentos de metodologia científica. 5ª . ed. São Paulo: Atlas, 2003.

LIBÂNEO, J. C. O dualismo perverso da escola pública brasileira: escola do conhecimento para os ricos, escola do acolhimento social para os pobres. Educação e Pesquisa, São Paulo, v. 38, n. 1, p. 13-28, jan./mar. 2012. https://doi.org/10.1590/S1517-97022011005000001

MELAZZO, E. S.; CASTRO, C. A. A escala geográfica: noção, conceito ou teoria? Terra Livre, Presidente Prudente, v. 2, n. 29, p. 133-142, ago./dez. 2007.

OLIVEIRA, R. F. C. A. Quais conceitos de escala pretendemos ensinar no ensino médio? Uma problematização a partir de suas definições nos livros didáticos de geografia $10^{\circ}$ Encontro Nacional de Prática de Ensino em Geografia. Anais... Porto Alegre: AGB. 2009.

PEREIRA, M. G. El currículo como espacio político: la batalla de la Geografía escolar por recomponer un sentido. In: RABELO, K. S. P.; BUENO, M. A. (Orgs.). Currículo, políticas públicas e ensino de Geografia. Goiânia: Editora da PUC/GO, 2015. Cap. 5, p. 103-133.

PIRES, L. M. Políticas educacionais e curriculares em curso no Brasil: a reforma do ensino médio e base nacional comum curricular (BNCC). In: ASCENÇÃO, V. O. R., et al. Conhecimentos da Geografia: percursos de formação docente e práticas na educação básica. Belo Horizonte: IGC, 2017. Cap. 11, p. 232-260.

VIGOTSKY, L. S. Pensamento e linguagem. São Paulo: Martins Fontes, 1993.

YOUNG, M. Para que servem as escolas? Educação e Sociedade, Campinas, v. 28, n. 101, p. 12871302, set./dez. 2007. https://doi.org/10.1590/S0101-73302007000400002

YOUNG, M. O futuro da educação em uma sociedade do conhecimento: o argumento radical em defesa de um currículo centrado em disciplinas. Revista Brasileira de Educação, Rio de Janeiro, v. 16, n. 48, p. 609-623, set./dez. 2011. https://doi.org/10.1590/S1413-24782011000300005

YOUNG, M. Por que o conhecimento é importante para as escolas do século XXI? Cadernos de Pesquisa, São Paulo, v. 46, n. 159, p. 18-37, jan./mar. 2016. https://doi.org/10.1590/198053143533

Recebido em: 29/07/2019

Aceito para publicação em: 24/01/2020 